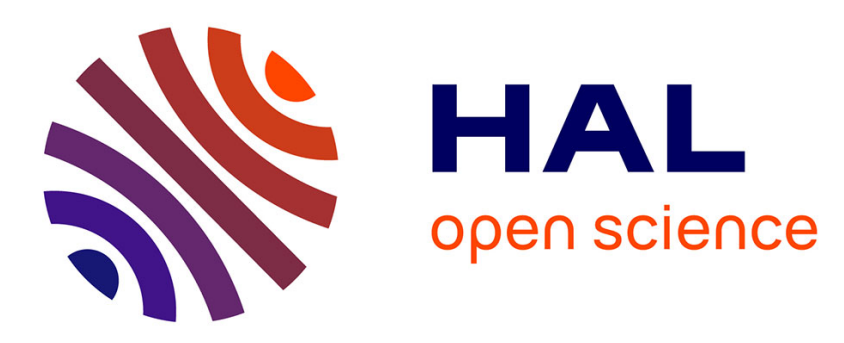

\title{
Lidar observations of ozone changes induced by subpolar air mass motion over Table Mountain, California
} $\left(34.4^{\circ} \mathrm{N}\right)$

\author{
Thomas Mcgee, Paul Newman, Richard Ferrare, David Whiteman, James \\ Butler, John Burris, Sophie Godin, I. Stuart Mcdermid
}

\section{To cite this version:}

Thomas Mcgee, Paul Newman, Richard Ferrare, David Whiteman, James Butler, et al.. Lidar observations of ozone changes induced by subpolar air mass motion over Table Mountain, California $\left(34.4^{\circ} \mathrm{N}\right)$. Journal of Geophysical Research: Atmospheres, 1990, 95 (D12), pp.20527-20530. 10.1029/JD095iD12p20527 . insu-03041869

\section{HAL Id: insu-03041869 \\ https://hal-insu.archives-ouvertes.fr/insu-03041869}

Submitted on 2 Feb 2021

HAL is a multi-disciplinary open access archive for the deposit and dissemination of scientific research documents, whether they are published or not. The documents may come from teaching and research institutions in France or abroad, or from public or private research centers.
L'archive ouverte pluridisciplinaire HAL, est destinée au dépôt et à la diffusion de documents scientifiques de niveau recherche, publiés ou non, émanant des établissements d'enseignement et de recherche français ou étrangers, des laboratoires publics ou privés. 


\title{
Lidar Observations of Ozone Changes Induced by Subpolar Air Mass Motion Over Table Mountain, California $\left(34.4^{\circ} \mathrm{N}\right)$
}

\author{
Thomas J. McGee, ${ }^{1}$ Paul Newman, ${ }^{1}$ Richard Ferrare, ${ }^{1}$ David Whiteman, ${ }^{2}$ James Butler, ${ }^{3}$ \\ John Burris, ${ }^{1}$ Sophie Godin, ${ }^{4}$ AND I. StUART MCDERMID ${ }^{4}$
}

\begin{abstract}
Between October 15 and November 8, 1988, the Goddard Space Flight Center mobile stratospheric lidar was in place at the (JPL) Table Mountain Facility (located at $34.4^{\circ} \mathrm{N}, 117.7^{\circ} \mathrm{W}$ ) for the purpose of intercomparing with the JPL lidar permanently stationed at the observatory. During the course of the intercomparison both lidar systems detected a significant change in the vertical profile of ozone lasting for several days. An analysis of meteorological data available from the National Meteorological Center has shown this change to be dynamical in origin due to the transport of subpolar air over Table Mountain.
\end{abstract}

\section{INTRODUCTION}

In October 1988 an ozone measurement intercomparison was held at the Jet Propulsion Laboratory (JPL) Table Mountain Facility in the San Gabriel Mountains east of Los Angeles $\left(34.4^{\circ} \mathrm{N}, 117.7^{\circ} \mathrm{W}\right)$. The purpose behind the intercomparison was to test the performance of two stratospheric lidars: the permanent JPL system housed at Table Mountain, and the mobile lidar built at NASA's Goddard Space Flight Center (GSFC). Both systems were funded by the NASA Upper Atmosphere Research Program for eventual inclusion in a network for the early detection of stratospheric change. Such a network is to be set up for the ground-based detection of long-term stratospheric trends [Watson, 1986] and would include a number of stations located at appropriate latitudes around the globe. During the course of the intercomparisons period, both lidars independently detected a large and sudden change in the ozone concentration between 24 and 35 $\mathrm{km}$. The maximum ozone depletion occurred at $27 \mathrm{~km}$ on October 20. This event was followed by a slow return to what was considered to be a "normal" profile. This paper reports the observations and the interpretation of the atmospheric phenomenon taking place from October 18-24.

\section{EXPERIMENT}

Both lidar systems have been previously described in detail [McDermid et al., 1990a, McGee et al., 1990]. Briefly, both are differential absorption lidars using $\mathrm{XeCl}$ excimer lasers to generate the on-line wavelength at $307.9 \mathrm{~nm}$. The systems differ, however, in the manner in which the off-line wavelength is generated. The GSFC instrument transmits the third harmonic of a Nd-YAG laser at $354.7 \mathrm{~nm}$. This laser operates at $16.5 \mathrm{~Hz}$, corresponding to every fourth shot of the excimer. The JPL lidar uses stimulated Raman scattering (SRS) in molecular hydrogen to generate $353 \mathrm{~nm}$ radiation.

\footnotetext{
${ }^{1}$ NASA Goddard Space Flight Center, Laboratory for Atmospheres, Greenbelt, Maryland.

${ }^{2}$ NASA Goddard Space Flight Center, Laboratory for Oceans, Greenbelt, Maryland.

${ }^{3}$ ST Systems Corporation, Lanham, Maryland.

${ }^{4}$ Jet Propulsion Laboratory, Table Mountain Facility, California Institute of Technology, Wrightwood.
}

Copyright 1990 by the American Geophysical Union.

Paper number 90JD01878.

0148-0227/90/90JD-01878\$05.00
Both of the off-line wavelengths have ozone absorption cross sections which are about 3 orders of magnitude lower than the on-line wavelengths. Because of the large solar flux at the transmitted wavelengths, the lidar systems currently make ozone measurements only at night. The lidars were physically separated by approximately $300 \mathrm{~m}$ during the intercomparison, but this separation was insufficient to avoid interference between the systems. Consequently it was necessary to operate the lidars sequentially rather than simultaneously. A detailed analysis of the data from the two lidars has been made and published elsewhere [McDermid et $a l ., 1990 b$ ]. The two systems agree very well between 20 and $40 \mathrm{~km}$. Because of this excellent agreement and the fact that the systems were operated over slightly different time intervals, the lidar data for each evening were combined to yield a single profile. These averaged profiles are discussed in this paper.

\section{Results AND Discussion}

The contour plots of Figure 1 contain the GSFC (Figure $1 a$ ) and the JPL (Figure $1 b$ ) data recorded during the intercomparison. The days on which data were taken are noted at the base of each figure. Data between these dates were obtained by interpolation. Between 20 and $40 \mathrm{~km}$, the agreement between the lidar data is quite good, as can be seen from the similarity between the plots. The plots show a marked depletion in ozone number density between 24 and $32 \mathrm{~km}$, occurring between October 18 and October 24. The largest change was measured at $27.5 \mathrm{~km}$ by both lidars on the night of October 20 . There was approximately a $30 \%$ change in ozone number density observed at this altitude between October 18 and 20 . The depletion at $27.5 \mathrm{~km}$ is also accompanied by a downward shift in the ozone maximum of about $2 \mathrm{~km}$. There is some recovery in the measured profiles after October 20, but the measured ozone concentration at these altitudes did not return to the levels of October 18.

Also evident in the figures is a sharp feature detected in the measurements made November 5. This feature was noted by the rocket, balloon, and satellite measurements made on the same day. An analysis of the available National Meteorological Center (NMC) data along with the chronology of the ozone soundings indicated that the dynamics of the ozone decrease occurred too rapidly to be captured by the available meteorological data, and so is not addressed in this publication. 


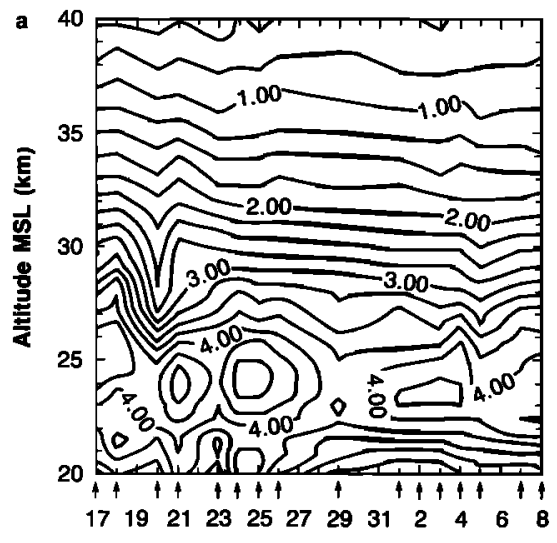

Date (October-November, 1988)

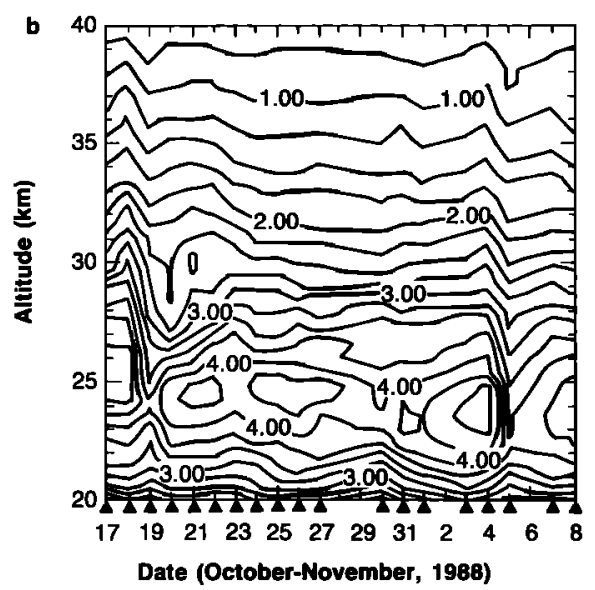

Fig. 1. Contour map of the (a) GSFC and (b) JPL ozone data between October 17 and November 8, 1988. Dates on which data were obtained are noted along the base of the figure. Other data were obtained by interpolation. Units are $10^{18} \mathrm{~m}^{-3}$.

Since the photochemical lifetime of odd oxygen is greater than 12 days at altitudes below $35 \mathrm{~km}$ [Garcia and Solomon, 1985], it is unlikely that the rapid depletion observed between October 18 and 20 is photochemical in origin. In order to assess the transport effects involved in the change, it is necessary to analyze the available meteorological data. Radiosonde measurements were obtained from Point Mugu, California $\left(34.2^{\circ} \mathrm{N}, 119.1^{\circ} \mathrm{W}\right)$ and from San Nicholas Island, California $\left(33.3^{\circ} \mathrm{N}, 119.5^{\circ} \mathrm{W}\right)$, while global stratospheric analyses were obtained from the Climate Analysis Center within the National Meteorological Center. These NMC analyses have been previously described in detail [Gelman et al., 1986].

Transport changes in ozone occur by either vertical or horizontal advection, or some combination of the two. For vertical advection, potential temperature $\theta$ can be used as a conserved vertical coordinate. Potential temperature is defined as the temperature $\theta$ a parcel of air would acquire if it were adiabatically brought to $1000 \mathrm{mbar}$

$$
\theta=T\left(P_{0} / P\right)^{\gamma}
$$

Here, $T$ is the temperature at the starting pressure $P ; P_{0}=$ $1000 \mathrm{mbar}$, and $\gamma=2 / 7$ (the ratio of the gas constant of dry air to the specific heat of dry air at constant pressure). The diabatic heating rate $Q$ can be expressed in terms of potential temperature:

$$
d \theta / d t=Q
$$

Under the condition that the diabatic heating rate is small (this is generally true; average diabatic heating rates for October at $35^{\circ} \mathrm{N}$ latitude in the altitude range $24-30 \mathrm{~km}$ have been calculated to be less than $1 \mathrm{~K} /$ day [Rosenfield et al., 1986]), potential temperature remains constant and air parcels then move quasi-adiabatically. Therefore an air parcel will tend to remain on a surface of constant potential temperature (which is an isentropic surface). For this reason, potential temperature is superior to geometric altitude as a vertical coordinate, since a parcel will remain on a potential temperature surface, whereas it can move over a large range of geometric altitude.

The horizontal motion of air masses can be best followed using Ertel's potential vorticity (EPV) on isentropic surfaces [Andrews et al., 1989]. Potential vorticity is calculated from the following expression:

$$
\mathrm{EPV}=-g(\xi+f) \frac{\partial \theta}{\partial P}
$$

where $g$ is the gravitational constant, $\xi$ is the relative vorticity, $f$ is the planetary vorticity, and $\theta$ is the potential temperature. EPV is in units of $\mathrm{km} /(\mathrm{kg} \mathrm{s})$ and has a typical mid-latitude value of approximately $10 \times 10^{-5}$ for the middle stratosphere. EPV is conserved for periods of the order of 1-3 weeks in the stratosphere when diabatic processes and frictional forces are small. Potential vorticity for a given isentropic surface has well-defined horizontal gradations. Typically, there are large values of EPV in the polar region, and smaller values in the tropics. The boundary between polar values and mid-latitude values is generally very sharp [Clough et al., 1987; Juckes and McIntyre, 1987]. The equator-pole gradient is not uniform, but it is small in both the polar and equatorial regions and is sharply peaked in the mid-latitudes. This sharp EPV gradient defines the boundary between polar and mid-latitude air.

Because rapid ozone changes took place between October 18 and 20 , the profiles obtained on these two nights have been used in the dynamical analysis. Radiosonde data from Point Mugu have been combined with the lidar number density data to form the volume mixing ratio. This is employed because unlike number density the mixing ratio is not influenced by local vertical motions when it is viewed on a potential temperature surface (i.e., mixing ratio is thus conserved along an isentropic surface). Figure 2 plots the calculated mixing ratio as a function of altitude. If vertical motion is the only mechanism considered, the mixing ratio shown in Figure 2 suggests that the ozone profile has been vertically lifted by $3-4 \mathrm{~km}$ in the $24-$ to $30-\mathrm{km}$ altitude range. Since the potential temperature is approximately conserved on this time scale, a local lifting of $3-4 \mathrm{~km}$ would induce an adiabatic cooling of approximately $30 \mathrm{~K}$. The plot of temperature versus altitude shown in Figure 3 shows that there has been a change of only $4-6 \mathrm{~K}$ at altitudes of interest over the days in question. Since the predicted adiabatic cooling calculated from the lifting of the ozone profile is inconsistent with the observed temperatures, vertical advection is not a significant source of the ozone reduction. The slight cooling 


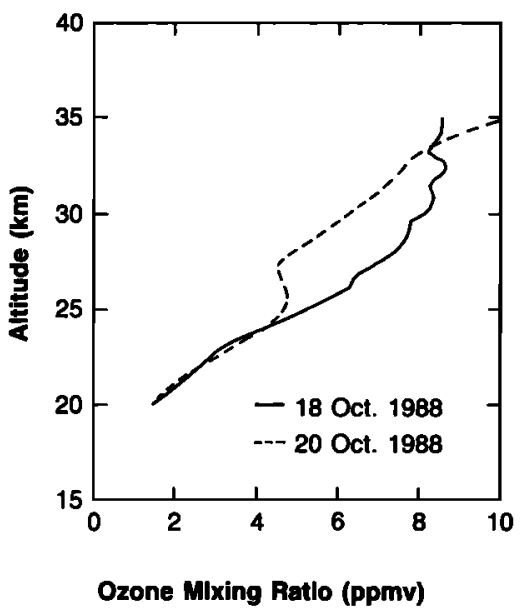

Fig. 2. A plot of the ozone volume mixing ratio as a function of altitude for October 18 and 20 . The mixing ratios were constructed from the combined lidar ozone profiles and the temperatures obtained from balloon sondes launched from Point Mugu and San Nicholas Island.

observed in the radiosonde data indicates a small lifting of about $0.5 \mathrm{~km}$.

The Ertel's potential vorticity plots derived from the NMC data show horizontal motion as the primary source of the ozone depletion. Figure 4 shows volume ozone mixing ratio as a function of potential temperature and indicates that the largest change in ozone mixing ratio occurred at $700 \mathrm{~K}$. Figures $5 a$ and $5 b$ show the EPV fields on the $700 \mathrm{~K}$ isentropic surface for October 18 and 20 , respectively. The thin solid lines are the EPV contours, while the thick solid line delineates the transition from easterly to westerly winds. The wind vectors are also displayed to indicate the direction of EPV movement. The winds are northwesterly in the North Pacific and eventually become westerly over the western coast of the United States. Figure $5 a$ shows a large high of potential vorticity extending southwestward from Vancouver Island into the Pacific Ocean. The winds advect this high potential vorticity systems southeastward, and by October 20 (Figure $5 b$ ) the disturbance has moved into a position over the central portion of the western United States. In the process of this movement, potential vorticity values have doubled over Table Mountain. Note that the

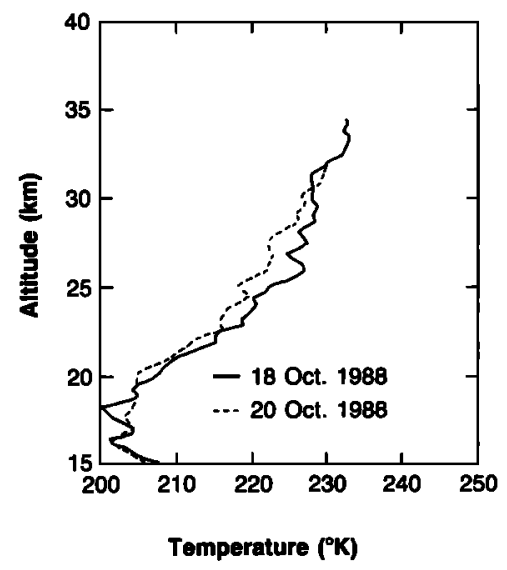

Fig. 3. The balloon temperature profiles measured on October 18 and 20.

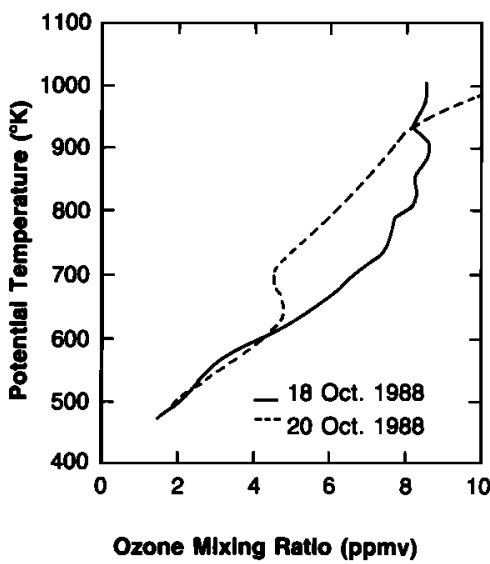

Fig. 4. Ozone volume mixing ratio as a function of potential temperature.

volume mixing ratio generally remains constant on an isentropic surface along the contours of constant potential vorticity. Therefore since the large values of potential vorticity observed over Table Mountain on October 20 are normally at latitudes substantially north of $34^{\circ}$, the observed ozone values are characteristic of early winter subpolar ozone, not mid-latitude ozone.

The horizontal ozone gradient can be estimated from the decrease in ozone mixing ratio between October 18 and 20.
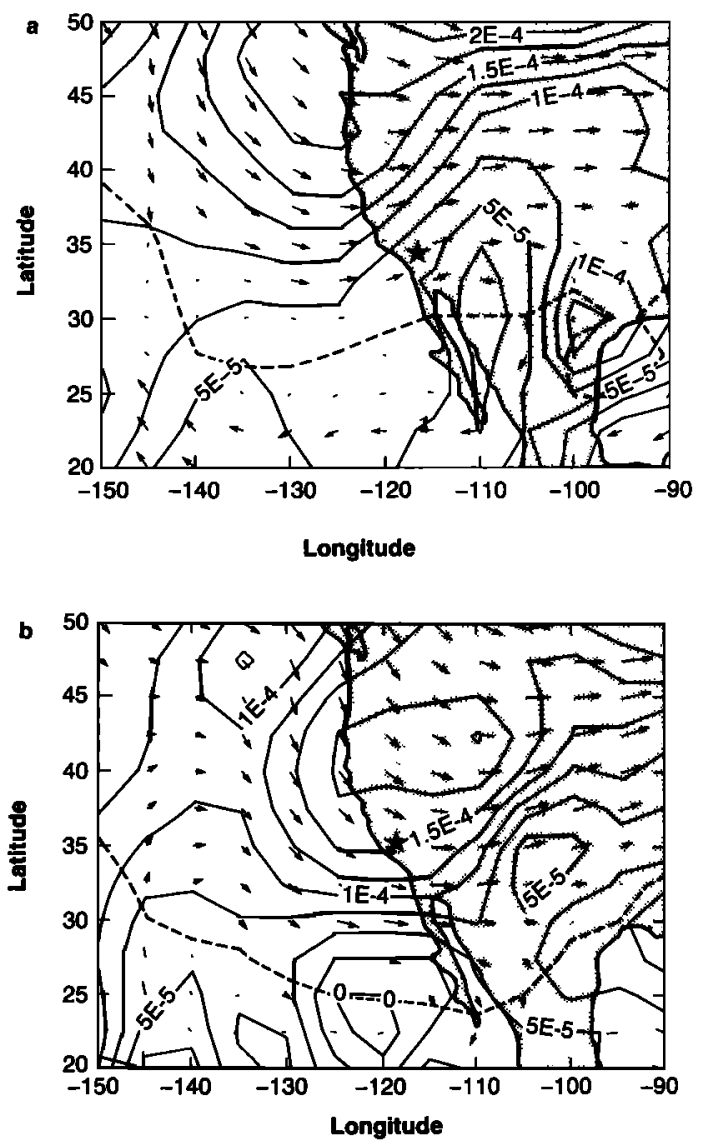

Fig. 5. Ertel's potential calculated for the $700 \mathrm{~K}$ potential temperature surface for $(a)$ October 18 and $(b)$ October 20. Table Mountain $\left(34^{\circ} \mathrm{N}, 117^{\circ} \mathrm{W}\right)$ is denoted by a star. The heavy dashed line is the boundary between easterly and westerly winds. 
The decrease in ozone mixing ratio was 3-4 ppmv at the 700 $\mathrm{K}$ potential temperature surface. The mixing ratio on October 18 is approximately associated with potential vorticity values near $7.5 \times 10^{-5}$ while on October 20 it is associated with potential vorticity values near $1.5 \times 10^{-4}$. If the average distance between these EPV contours is taken to be $400 \mathrm{~km}$, then the mixing ratio gradient near Table Mountain is approximately $-1.0 \times 10^{-2} \mathrm{ppmv} / \mathrm{km}$. Using the 10 -mbar solar backscatter ultraviolet (SBUV) mixing ratios of $\mathrm{Naga}$ tani et al., [1988] we can estimate an average gradient of $-1.6 \times 10^{-3}$ in the zonal mean at $35^{\circ} \mathrm{N}$. This mean gradient is 6 times smaller than that estimated from the lidar and potential vorticity measurements.

The disparity between the lidar/EPV-estimated gradient and the SBUV mean data is almost certainly due to the SBUV monthly and zonal averaging. As is shown in Figure 5 , the vortex is far from zonally symmetric. Hence the zonal averaging produces a smeared image of the rather sharp vortex boundary. The large depletion between October 18 and 20 indicates large zonal asymmetry in the mid-latitudes, and the large horizontal ozone gradients.

\section{SUMMARY}

We have made lidar measurements of the vertical profile of ozone above Table Mountain and observed a large decrease in ozone density between 24 and $32 \mathrm{~km}$. The perturbation lasted several days and was observed independently by both the JPL and GSFC lidars. An analysis of the available meteorological data has shown that the decrease was caused by an influx of subpolar air over the lidar site. A much sharper gradient between high-latitude air and midlatitude air was measured by the lidars than had previously been reported based on satellite measurements.

Acknowledgments. The funding for both lidar instruments was provided by the NASA Upper Atmosphere Research Program. We would particularly like to thank the staff from the JPL Table Mountain Facility for their assistance throughout the intercomparison. P.N. and R.F. are University Space Research Associates.

\section{REFERENCES}

Andrews, D. G., J. R. Holton, and C. B. Leovy, Middle Atmospheric Dynamics, pp. 115, 139-141, Academic, San Diego, Calif., 1989.
Clough, S. A., N. S. Grahame, and A. O'Neil, Potential vorticity in the stratosphere derived using satellites, Q.J.R. Meteorol. Soc., $111,335,358,1985$.

Garcia, R. R., and S. Solomon, The effect of breaking gravity waves on the dynamics and chemical structure of the mesophere and lower thermosphere, J. Geophys. Res., 90, 3850-3868, 1985.

Gelman, M. E., A. J. Miller, K. W. Johnson, and R. M. Nagatani, Detection of long-term trends in global stratospheric temperature from NMC analyses derived from NOAA satellite data, $A d v$. Space Res., 6, 17-25, 1986.

Juckes, M. N., and M. E. Mclntyre, A high resolution, one-layer model of breaking gravity waves in the stratosphere, Nature, 328 , 590, 1987.

McDermid, I. S., S. M. Godin, and L. O. Linqvist, Ground-based laser dial system for long-term measurements of stratospheric ozone, Appl. Opt., 29, 3603-3612, 1990a.

McDermid, I. S., S. M. Godin, L. O. Linqvist, T. D. Walsh, J. Burris, J. Butler, R. Ferrare, D. Whiteman, and T. J. McGee, Measurement intercomparison of the JPL and GSFC stratospheric ozone lidar systems, Appl. Opt., in press, $1990 \mathrm{~b}$.

McGee, T. J., D. Whiteman, R. Ferrare, J. Butler, and J. Burris, STROZ Lite: NASA/GSFC stratospheric ozone lidar trailer experiment, Opt. Eng., in press, 1990.

Nagatani, R. M., A. J. Miller, K. W. Johnson, and M. E. Gelman, An eight-year climatology of meteorological and SBUV ozone data, NOAA Tech. Rep. NWS 40, 1988.

Rosenfield, J. E., M. R. Schoeberl, and M. A. Geller, A computation of stratospheric diabatic residual circulation using an accurate radiative transfer mode, J. Atmos. Sci., 44, 859-876, 1987.

Watson, R. T. (Ed.), Network for the Detection of Stratospheric Change, Report of the Workshop, Upper Atmosphere Research Program, NASA, Washington, D. C., 1986.

J. Burris, R. Ferrare, T. J. McGee, and P. Newman, Laboratory for Atmospheres, NASA Goddard Space Flight Center, Greenbelt, MD 20771.

J. Butler, ST Systems Corporation, 4400 Forbes Boulevard, Lanham, MD 20707.

S. Godin and I. S. McDermid, Table Mountain Facility, Jet Propulsion Laboratory, California Institute of Technology, Wrightwood, CA 92397.

D. Whiteman, Laboratory for Oceans, NASA Goddard Space Flight Center, Greenbelt, MD 20771.
(Received October 31, 1989; revised August 16, 1990; accepted August 20, 1990.) 